\title{
钯一催化芳香杂环烯炔的不对称环化异构化反应
}

\author{
赵平奕新军* \\ (西北大学化学与材料科学学院 教育部合成天然功能分子重点实验室 西安 710127)
}

\section{Palladium-Catalyzed Enantioselective Heteroarenyne Cycloisomerization Reaction}

\author{
Zhao, Ping Luan, Xinjun* \\ (Key Laboratory of Synthetic and Natural Functional Molecule of the Ministry of Education, \\ College of Chemistry \&Materials Science, Northwest University, Xi'an 710127)
}

自然界中许多光学活性分子都含有高度官能化的 碳环和杂环. 这些重要的结构特征, 往往是分子具有生 物活性和特定功能所必需的, 为此合成化学家一直在寻 找有效的方法来合成这些化合物 ${ }^{[1]} .1, n$-烯炔的 ene 型环 异构化反应能直接、有效地合成环状 1,4-二烯分子 (Scheme 1) $)^{[2]}$. 此类方法是利用一些简单易得的底物制 备一些具有复杂结构的环状化合物. 具有原子经济性 高, 对环境友好的特点, 已成为了一种极具吸引力的合 成方法. 自 1985 年 Trost 等 ${ }^{[3]}$ 开创性地报道了 1,6-烯炔 的环异构化反应以来，过渡金属( Ti、 Co、 Fe、Rh、Ru、 $\mathrm{Ni}-\mathrm{Cr} 、 \mathrm{Pd} 、 \mathrm{Pt} 、 \mathrm{Au}$ )催化的烯炔环异构化反应得到了快 速发展 ${ }^{[4]}$, 并已广泛应用于天然产物的全合成 ${ }^{[5]}$. 同时, 在各种手性催化剂作用下, 反应能将 $1, n$-烯炔类底物高 效转化为光学活性环状化合物.

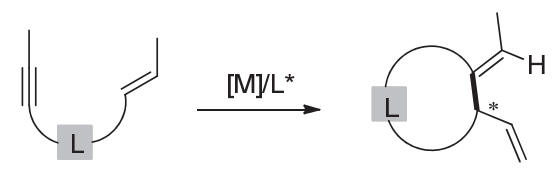

图式 $11, n$-烯炔的 ene 型环异构化反应

Scheme 1 Ene-type cycloisomerization of $1, n$-enyne

最近, 以迁移插入策略打破芳香体系的不对称去芳 构化反应备受关注 ${ }^{[6-8]}$. 目前, 利用芳香化合物的环内 碳一碳双键为偶联片段, 不对称 Heck 反应、还原 Heck 反应以及 Heck 串联捕获反应已得到广泛研究. 然而, 利用 $\mathrm{PdH}$-催化启动, 实现芳香环内碳一碳双键迁移插入 及随后的 $\beta-\mathrm{H}$ 消除过程的去芳构化转化反应却一直没有 报道. 如何准确、有效地实现该反应过程具有巨大挑战 性. 近日, 浙江工业大学化工学院贾义霞课题组报道了
PdH-催化芳香杂环烯炔的不对称环异构化去芳构化反 应, 实现了一系列螺环或并环吲哚啉衍生物的高对映选 择性合成(Scheme 2) ${ }^{[9]}$, 所得含氮杂环骨架结构广泛存 在于天然产物中 ${ }^{[10]}$ 。该方法不仅能利用简单易得的底 物构建出结构复杂的多环吲哚啉分子, 同时还使环异构 化反应得以进一步丰富和完善.

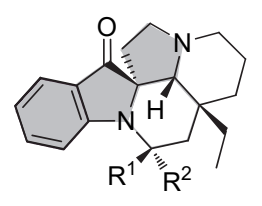

melokhanine B-E

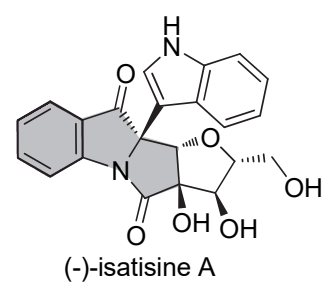

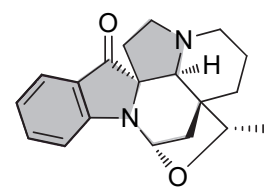

(+)-larutienine B

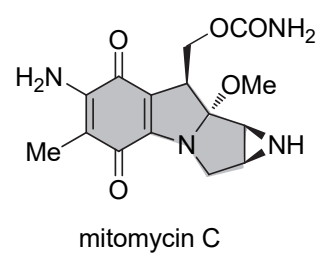

图式 2 含有螺环或并环吲哚啉结构的天然产物 Scheme 2 Selected natural products containing spiro- or fusedindoline scaffold

在金属钯催化下, $N$-或 C2-炔基支链取代吲哚底物, 先后经过分子间的氢钯化及分子内的 Heck 烯基化反应 过程, 实现吲哚环内碳一碳双键的不对称去芳构化转化, 为螺环或并环吲哚啉类化合物的合成提供了一种便捷 的方法(Scheme 3). 该反应具有中等至较优的收率、良 好的官能团兼容性以及优异的对映选择性. 作者首先以 吲哚 $\mathrm{C} 2$ 位带有炔基支链的形式 1,6-烯炔化合物为底物, 手性亚磷酰胺酯为配体, $\mathrm{Ph}_{3} \mathrm{CCO}_{2} \mathrm{H}$ 为氢源, 通过不对

\footnotetext{
* Corresponding author. E-mail: xluan@nwu.edu.cn. Published online May 10, 2021.
} 


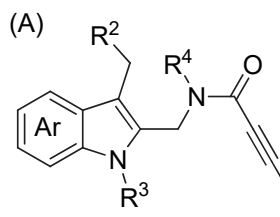

C2-tethered indole

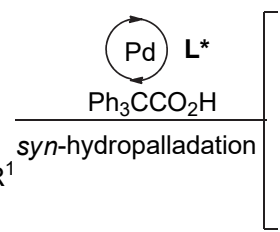

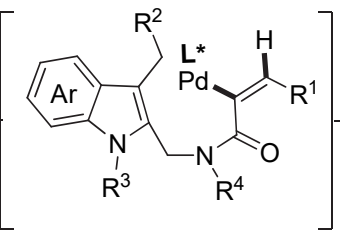

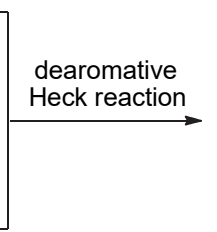

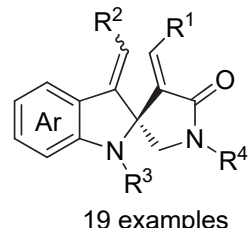

up to $98 \%$ ee

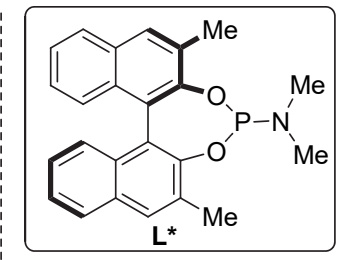

(B)

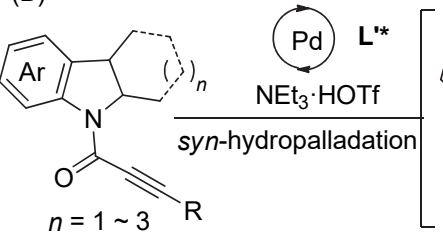

$n=1 \sim 3 \mathrm{R}$

$N$-tethered indole

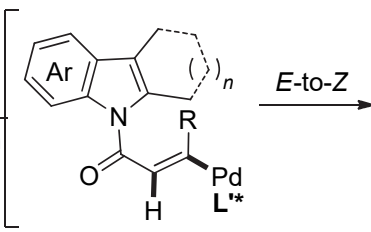

$\mathrm{H} \quad \mathbf{L}^{* *}$

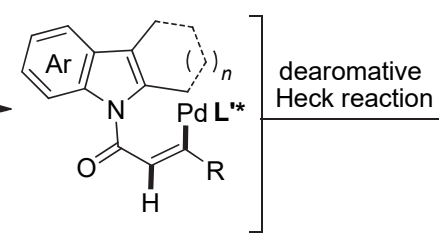

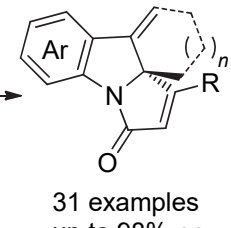

up to $98 \%$ ee

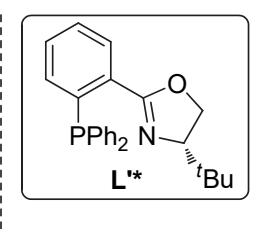

图式 3 PdH-催化不对称芳香杂环烯炔的环化异构化

Scheme 3 PdH-catalyzed enantioselective heteroarenyne cycloisomerization

称芳香杂环烯炔环异构化反应获得手性的螺环吲哚啉 结构产物, 其 $e e$ 值最高可达 $98 \%$. 随后, 作者进一步研 究了吲哚 $\mathrm{N}$ 上带有炔基支链的形式 1,5-烯炔化合物的不 对称环异构化反应. 在以 (S)- ${ }^{-} \mathrm{Bu}-\mathrm{PHOX}$ 作为手性配体, $\mathrm{NEt}_{3} \cdot \mathrm{HOTf}$ 为氢源的条件下, 反应以最高 $98 \%$ 的 $e e$ 值顺 利转化为手性并环吲哚啉产物. 基于实验结果, 作者提 出该 1,5-烯炔环异构化反应可能经历烯炔的顺式氢钯 化、烯基钯物种的 $E / Z$ 异构化及分子内 Heck 串联反应 过程, 实现吲哚的不对称去芳构化. 为了验证反应中的 负氢来源, 作者进行了氛代实验, 结果表明负氢可能来 源于酸添加剂.

在成功实现 PdH 催化 $N$-炔基支链取代吲哚的不对 称 1,5-芳香杂环烯炔去芳构环异构化反应后, 作者进一 步研究了经典 1,5-烯炔化合物的不对称环异构化反应. 结果表明, 在以 $\mathrm{Pd}_{2} \mathrm{dba}_{3} \cdot \mathrm{CHCl}_{3}$ 为催化剂前体, 手性亚 磷酰胺酯为配体, $\mathrm{BnOH}$ 为添加剂的条件下, $N$-乙烯基丙 烯酰胺底物能以中等的收率和较优的对映选择性转化 为 2-吡咯烷酮类化合物(Scheme 4).

综上所述, 作者以带有炔基支链的吲哚为底物, 发 展了 PdH-催化芳香杂环烯炔的不对称环异构化反应. 合成了一系列结构多样性的手性螺环或并环吲哚啉类 化合物, 获得中等至良好的收率以及良好至优异的对映 选择性, ee 值最高可达到 $98 \%$. 随后, 作者进行了一系 列转化实验. 所得产物经氢化、还原、氧化、BaeyerVilliger 重排以及[3+2]环加成反应等转化为相应的手

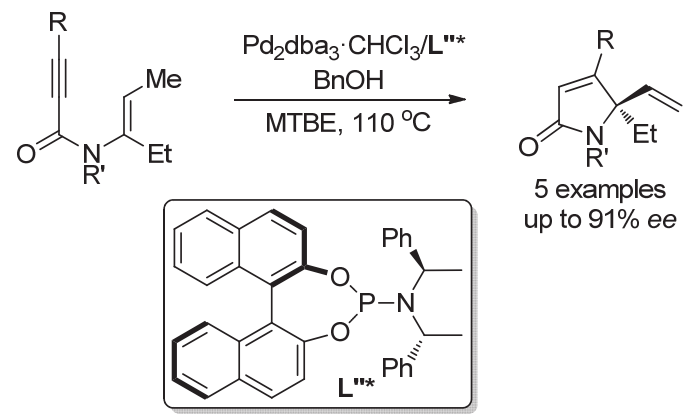

图式 $4 \mathrm{~N}$-乙烯基丙烯酰胺的不对称 1,5-烯炔环异构化反应 Scheme 4 Enantioselective 1,5-enyne cycloisomerization of $\mathrm{N}$-vinylpropiolamide

性含氮杂环化合物, 此过程中对映选择性得到良好的保 持.

\section{References}

[1] Fairlamb, I. J. S. Angew. Chem., Int. Ed. 2004, 43, 1048.

[2] Watson, I. D. G.; Toste, F. D. Chem. Sci. 2012, 3, 2899.

[3] Trost, B. M.; Lautens, M. J. Am. Chem. Soc. 1985, 107, 1781.

[4] Michelet, V.; Toullec, P. Y.; Genêt, J.-P. Angew. Chem., Int. Ed. 2008, 47, 4268 .

[5] Chen, Y.; Ding, Z.; Wang, Y.; Liu, W.; Kong, W. Angew. Chem., Int. Ed. 2021, 60, 5273.

[6] Zhuo, C.-X.; Zhang, W.; You, S.-L. Angew. Chem., Int. Ed. 2012, 51,12662

[7] Zhuo, C.-X.; Zheng, C.; You, S.-L. Acc. Chem. Res. 2014, 47, 2558.

[8] Zheng, C.; You, S.-L. Chem 2016, 1, 830.

[9] Liang, R.-X.; Song, L.-J.; Lu, J.-B.; Xu, W.-Y.; Ding, C.; Jia, Y.-X. Angew. Chem., Int. Ed. 2021, 60, 7412.

[10] Chong, K.-W.; Yeap, J. S.-Y.; Lim, S.-H.; Weber, J.-F. F.; Low, Y.-Y.; Kam, T.-S. J. Nat. Prod. 2017, 80, 3014. 